\title{
Erratum to: Garnet and spinel in fertile and depleted mantle: insights from thermodynamic modelling
}

\author{
Luca Ziberna $\cdot$ Stephan Klemme $\cdot$ Paolo Nimis
}

Published online: 2 August 2014

(C) Springer-Verlag Berlin Heidelberg 2014

\section{Erratum to: Contrib Mineral Petrol (2013) 166:411-421 \\ DOI 10.1007/s00410-013-0882-5}

In the electronic supplementary file, one of the thermodynamic data is imperfectly reported as 30000 instead of 3000. The error has occurred in Table 1, section Solid solution parameters (last row of the column Wa). The corrected table is provided here.

The online version of the original article can be found under doi:10.1007/s00410-013-0882-5.

Electronic supplementary material The online version of this article (doi:10.1007/s00410-014-1036-0) contains supplementary material, which is available to authorized users.

L. Ziberna $\cdot$ P. Nimis

Dipartimento di Geoscienze, Universitä di Padova,

Via Gradenigo 6, 35131 Padua, Italy

L. Ziberna $(\bowtie)$

Bayerisches Geoinstitut, Universität Bayreuth,

95440 Bayreuth, Germany

e-mail: luca.ziberna@uni-bayreuth.de

\section{S. Klemme}

Institut für Mineralogie, Universität Münster,

Corrensstr. 24, 48149 Münster, Germany

P. Nimis

IGG-CNR, Padua, Italy 